\title{
Kinetic disruption of optical texture: The perception of depth at an edge'
}

\author{
GEORGE A. KAPLAN ${ }^{2}$ \\ STANFORD UNIVERSITY
}

\begin{abstract}
An examination of the changes in visual stimulation that result from changes in the occlusion of one surface or object by another suggests two hypotheses about the motion-carried information that is sufficient for the perception of the relative depth at an edge as well as the perception of occlusion. Ss' reports when shown displays containing only this information give strong support to the hypotheses.
\end{abstract}

Terrestrial animals have presumably evolved to move about in an environment that consists of, among other things, extended surfaces with cliffs, caves, detachable objects, and trees. An important fact about such an environment is the occluding, covering, or hiding of one thing by another. That is, from a given point in space some objects and some surfaces will be temporarily hidden from view while others will be visible.

Occluding edges and the spatial relationships implied by them are involved in the traditional study of interposition or superposition as a monocular cue for relative depth. However, starting with the conjecture of Helmholtz (1962, p. 284), extending through the studies of Chapanis and McCleary (1953), and Dinnerstein and Wertheimer (1957) there has been no real success in finding the sufficient proximal information for the perception of occlusion. The position taken here is that if only the static visual stimulus-the frozen pictorial aspect of stimulation-is considered, there will probably continue to be little success. However, if the more representative situation of changes in superposition is considered, there may be a solution. There are, after all, good reasons for considering the motion-carried aspects of stimulation. Previous attempts at an analysis of such information have demonstrated that they might consistute an important source of information for the visual system (Gibson, 1966, 1968a;3 Hay, 1966; Johannson, 1964; Braunstein, 1966). The present study consists of an attempt to specify the changes in proximal stimulation that stem from changes in the location of two surfaces, one of which is partially occluding the other.

Consider that as a consequence of an O's movement or motion of an object relative to an $\mathrm{O}$, there are changes in the surfaces or parts of surfaces that are projected to the station point at which the O's eye is located. 4 Figure 1 illustrates the nature of these changes for the case in which one surface moves past, and thereby covers, another surface. The letters and numbers represent elements of the surface texture and the optical texture (no particular definition of texture element is assumed; however, it is assumed that there is a one-to-one mapping from surface element to optical element). Note that as the right-hand surface progressively occludes the left-hand surface parts of the latter are deleted from the optic array. If the event were reversed then parts of the left-hand surface would be accreted to the array. This optical transformation of accretion/deletion of texture elements is defined with respect to the proximal array only and, for the present discussion, will be taken to be the progressive removal or addition of adjacent elements of the optical texture at some location in the optic array.

It is clear in the above example that the specific changes that occur in the optic array from Time 1 to Time 2 specify the direction of depth at the edge: The surface that maintains the projection of its elements will be the occluding surface, and thus in front, and the surface which has its optical elements deleted or accreted will be the occluded surface, and thus in back. It is possible to generalize on the basis of this example to the following general hypothesis:

Hypothesis 1 (H1)-Whenever there is progressive optical accretion or deletion of units of an optical texture on one side of a margin in an optic array, and preservation of the units of the optical texture on the other side of the margin, then the region that undergoes the accretion/deletion will be seen as a surface that is behind another surface corresponding to the region in which the elements are preserved. Thus, an edge will be seen with a specific direction of depth.

This hypothesis can be seen to involve the opposition of accretion/deletion of optical texture with that of preservation of optical texture. There is, however, another possible hypothesis. Specifically, instead of opposing accretion/deletion with preservation of texture units, it is possible to introduce the notion of rate or frequency of accretion/deletion, e.g., the number of elements of texture accreted or deleted per unit of time. Preservation of optical texture would then correspond to accretion/deletion at a rate $=0$. With respect to this formulation, the direction of depth at an edge is specified by a measure that reflects the disparity or difference of rates of accretion/deletion on each side of a given margin in an array.

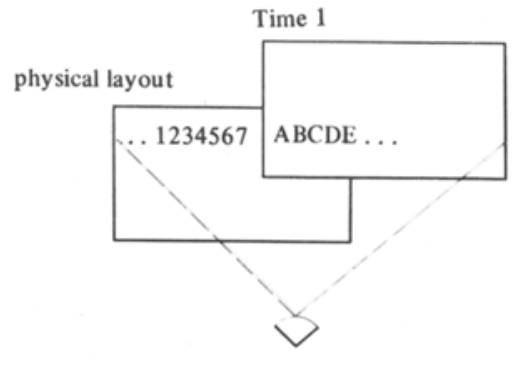

optic array

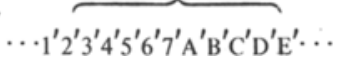

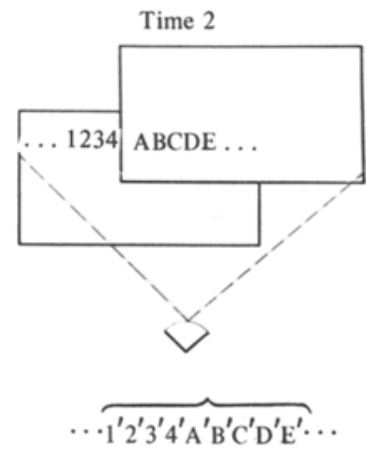

Fig. 1. Schematic representation of two successive optic arrays and their source. 
Hypothesis 2 (H2)-Whenever there is progressive optical accretion/deletion of units of optical texture along a margin in an optic array, then the region that undergoes the greater amount of accretion/deletion per interval of time will be seen as a surface that is behind another surface that corresponds to the region in which the rate of accretion/deletion is lesser. Thus again, the hypothesis predicts that an edge with a specific direction of depth will be perceived.

Note that this hypothesis says nothing about the amount of disparity that is present. Since there are no a priori reasons for thinking that such a measure would have any particular significance, it seems best to state the hypothesis in a purely ordinal fashion. Thus, the region that has more optical accretion/deletion will be seen behind, the region that has less will be seen in front.

Neither hypothesis puts any special constraints (other than threshold constraints) on the absolute or relative motions of the two surfaces that project their elements into the array. The hypotheses are thus appropriate for events in which one surface goes behind another surface or comes out from behind another, for events in which a surface is covered or uncovered by another, or for ecologically "implausible" displays that are artificially produced in the laboratory. In addition, the first hypothesis is logically contained within the second in that all predictions made by the first will also be made by the second, but not vice versa; the second hypothesis makes predictions about sequences that are not relevant to the first hypothesis.

In order to confirm either hypothesis it is necessary to present Ss with displays in which the only information for edge depth is that specified by the optical accretion/deletion transformation. That is, all other traditional cues for the perception of relative depth must be eliminated. Since the analyses are based on an examination of the changes in stimulation that result from changes in occlusion when one surface moves relative to another, and on extensions of these analyses, it is necessary to use displays that represent moving surfaces. In order to demonstrate the generality of the hypotheses it is necessary to show that what is important is not the motion of the surfaces but, rather, the accretion/deletion that is linked to these motions. Thus, variation in rate and direction of motion of these surfaces with invariant accretion/deletion is called for.

Lastly, strong support can be gained for the second of the two hypotheses by looking at displays where the hypothesis predicts no depth will be seen-e.g., those in which there is

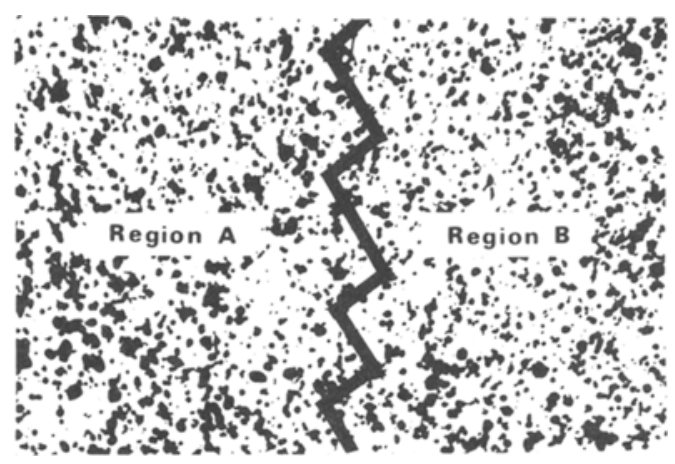

Fig. 2. Display format.

accretion/deletion on both sides of a margin but in which the disparity of the rate of accretion/deletion across the margin $=0$.

\section{METHOD}

Displays

A total of 41 16-mm film sequences, each 140 frames long, were constructed by means of single-frame animation techniques. The display format was a rectangular area divided into two adjacent sections each of which was filled with a randomly textured surface (Fig. 2). 5 The display appeared to be a single continuous randomly textured surface when motionless, there being no contour between the two sections. Each sequence consisted of 20 frames in which the textures were stationary at the beginning and end of the film, and 100 frames in which the textures in the two regions (A and $B$ ) were displaced in the manner specified by the experimental design.

The description of the 41 sequences is as follows: In one group of sequences (Table 1), the textures in Region $A$ and/or B could be moved to the right or to the left, or one could be stationary. When both moved, they were displaced at one of two rates; one moved at $.016 \mathrm{in} / \mathrm{sec}$ (Rate 1) and the other moved at $.031 \mathrm{in} . / \mathrm{sec}$ (Rate 2 ), or both moved at Rate 1 . Thus, all possible horizontal motions and rates of motion for the specified format are represented. The margin at which the optical accretion/deletion transformation took place was stationary and was randomly positioned at the center or $1 / 3$ left or right of the center of the frame.

Table 1

\begin{tabular}{|c|c|c|c|c|c|c|c|}
\hline $\begin{array}{c}\text { Sequence } \\
\text { Number }\end{array}$ & $\begin{array}{l}\text { Motion } \\
\text { in } \mathrm{A}\end{array}$ & $\begin{array}{l}\text { Motion } \\
\text { in B }\end{array}$ & $\begin{array}{l}\text { Relative } \\
\text { Velocity }\end{array}$ & $\begin{array}{l}\text { Relative } \\
\text { Acc./Del. }\end{array}$ & Disparity & $\begin{array}{l}\text { Relevant } \\
\text { Hypothesis }\end{array}$ & $\begin{array}{l}\text { Proportion } \\
\text { Correctly } \\
\text { Predicted } \\
\end{array}$ \\
\hline $\begin{array}{l}10 \\
19 \\
37 \\
28\end{array}$ & $\begin{array}{l}\mathbf{L} \\
\mathbf{L} \\
\mathbf{R} \\
\mathbf{R}\end{array}$ & $\begin{array}{l}\mathrm{L} \\
\mathrm{R} \\
\mathbf{L} \\
\mathrm{R}\end{array}$ & $\begin{array}{l}\mathbf{A}=\mathbf{B} \\
\mathbf{A}=\mathbf{B} \\
\mathbf{A}=\mathbf{B} \\
\mathbf{A}=\mathbf{B}\end{array}$ & $\begin{array}{l}\mathbf{A}=\mathbf{B} \\
\mathbf{A}=\mathbf{B} \\
\mathbf{A}=\mathbf{B} \\
\mathbf{A}=\mathbf{B}\end{array}$ & $\begin{array}{l}0 \\
0 \\
0 \\
0\end{array}$ & $\begin{array}{l}2 \\
2 \\
2 \\
2\end{array}$ & $\begin{array}{l}.86 \\
.70 \\
.53 \\
.83\end{array}$ \\
\hline $\begin{array}{r}1 \\
3 \\
5 \\
7 \\
11 \\
12 \\
20 \\
21 \\
38 \\
39 \\
29 \\
30\end{array}$ & $\begin{array}{l}\text { L } \\
\text { R } \\
\text { St } \\
\text { St } \\
\text { L } \\
\text { L } \\
\text { L } \\
\text { L } \\
\text { R } \\
\text { R } \\
\text { R } \\
\text { R }\end{array}$ & $\begin{array}{l}\text { St } \\
\text { St } \\
\text { L } \\
\text { R } \\
\text { L } \\
\text { L } \\
\text { R } \\
\text { R } \\
\text { L } \\
\text { L } \\
\text { R } \\
\text { R }\end{array}$ & $\begin{array}{l}A \geq B \\
A \geq B \\
A<B \\
A<B \\
A>B \\
A<B \\
A>B \\
A<B \\
A>B \\
A<B \\
A>B \\
A<B\end{array}$ & $\begin{array}{l}A>B \\
A \geq B \\
A<B \\
A<B \\
A>B \\
A<B \\
A>B \\
A<B \\
A>B \\
A<B \\
A>B \\
A<B\end{array}$ & $\begin{array}{l}1 \\
1 \\
1 \\
1 \\
1 \\
1 \\
1 \\
1 \\
1 \\
1 \\
1 \\
1\end{array}$ & $\begin{array}{r}1,2 \\
1,2 \\
1,2 \\
1,2 \\
2 \\
2 \\
2 \\
2 \\
2 \\
2 \\
2 \\
2\end{array}$ & $\begin{array}{r}1.00 \\
1.00 \\
1.00 \\
1.00 \\
.58 \\
.66 \\
.53 \\
.66 \\
.69 \\
.61 \\
.81 \\
.62\end{array}$ \\
\hline
\end{tabular}

$L=$ Move to left

$R=$ Move to right

$S t=$ Stationary 
Table 2

\begin{tabular}{|c|c|c|c|c|c|c|c|c|c|}
\hline $\begin{array}{l}\text { Sequence } \\
\text { Number }\end{array}$ & $\begin{array}{l}\text { Motion } \\
\text { in } \mathrm{A}\end{array}$ & $\begin{array}{l}\text { Motion } \\
\text { In } B\end{array}$ & $\begin{array}{c}\text { Motion } \\
\text { of } \\
\text { Margin }\end{array}$ & $\begin{array}{c}\text { Margin } \\
\text { Rate }\end{array}$ & $\begin{array}{l}\text { Relative } \\
\text { Velocity }\end{array}$ & $\begin{array}{l}\text { Relative } \\
\text { Acc./Del. }\end{array}$ & Disparity & $\begin{array}{l}\text { Relevant } \\
\text { Hypothesis }\end{array}$ & $\begin{array}{l}\text { Proportion } \\
\text { Correctly } \\
\text { Predicted }\end{array}$ \\
\hline 104 & $\mathbf{R}$ & $\mathbf{R}$ & $\mathbf{R}$ & 1 & $A=B$ & $A=B$ & 0 & 1,2 & \\
\hline $\begin{array}{l}100 \\
103 \\
101 \\
102 \\
106 \\
131 \\
109 \\
134 \\
112 \\
137\end{array}$ & $\begin{array}{l}R \\
R \\
R \\
R \\
R \\
L \\
R \\
L \\
R \\
L\end{array}$ & $\begin{array}{l}R \\
R \\
R \\
R \\
L \\
R \\
L \\
R \\
L \\
R\end{array}$ & $\begin{array}{l}\mathbf{R} \\
\mathbf{R} \\
\mathbf{R} \\
\mathbf{R} \\
\mathbf{R} \\
\mathbf{R} \\
\mathbf{R} \\
\mathbf{R} \\
\mathbf{L} \\
\mathbf{L}\end{array}$ & $\begin{array}{l}2 \\
2 \\
1 \\
1 \\
1 \\
1 \\
1 \\
1 \\
1 \\
1\end{array}$ & $\begin{array}{l}A \geq B \\
A<B \\
A \geq B \\
A<B \\
A \geq B \\
A<B \\
A=B \\
A=B \\
A<B \\
A>B\end{array}$ & $\begin{array}{l}\mathrm{A}<\mathrm{B} \\
\mathrm{A} \geq \mathrm{B} \\
\mathrm{A} \geq \mathrm{B} \\
\mathrm{A}<\mathrm{B} \\
\mathrm{A}<\mathrm{B} \\
\mathrm{A} \geq \mathrm{B} \\
\mathrm{A}<\mathrm{B} \\
\mathrm{A} \geq \mathrm{B} \\
\mathrm{A} \geq \mathrm{B} \\
\mathrm{A}<\mathrm{B}\end{array}$ & $\begin{array}{l}1 \\
1 \\
1 \\
1 \\
1 \\
1 \\
1 \\
1 \\
1 \\
1\end{array}$ & $\begin{array}{c}1,2 \\
1,2 \\
1,2 \\
1,2 \\
2 \\
2 \\
1,2 \\
1,2 \\
2 \\
2\end{array}$ & $\begin{array}{r}.97 \\
.95 \\
.98 \\
.91 \\
.91 \\
.86 \\
1.00 \\
1.00 \\
.91 \\
.83\end{array}$ \\
\hline $\begin{array}{l}114 \\
139\end{array}$ & $\begin{array}{l}\mathbf{R} \\
\mathbf{L}\end{array}$ & $\begin{array}{l}\mathrm{L} \\
\mathrm{R}\end{array}$ & $\begin{array}{l}\mathrm{L} \\
\mathrm{L}\end{array}$ & $\begin{array}{l}1 \\
1\end{array}$ & $\begin{array}{l}\mathbf{A}=\mathbf{B} \\
\mathbf{A}=\mathbf{B}\end{array}$ & $\begin{array}{l}A \geq B \\
A<B\end{array}$ & $\begin{array}{l}2 \\
2\end{array}$ & $\begin{array}{l}1,2 \\
1,2\end{array}$ & $\begin{array}{r}.97 \\
1.00\end{array}$ \\
\hline $\begin{array}{l}105 \\
130 \\
107 \\
122 \\
108 \\
133 \\
110 \\
135 \\
111 \\
136 \\
113 \\
138 \\
\end{array}$ & $\begin{array}{l}\text { R } \\
\text { L } \\
\text { R } \\
\text { L } \\
\text { R } \\
\text { L } \\
\text { R } \\
\text { L } \\
\text { R } \\
\text { L } \\
\text { R } \\
\text { L }\end{array}$ & $\begin{array}{l}\text { L } \\
R \\
\text { L } \\
R \\
\text { L } \\
\text { R } \\
\text { L } \\
\text { R } \\
\text { L } \\
\text { R } \\
\text { L } \\
\text { R }\end{array}$ & $\begin{array}{l}\text { R } \\
\text { R } \\
\text { R } \\
\text { R } \\
\text { R } \\
\text { R } \\
\text { L } \\
\text { L } \\
\text { L } \\
\text { L } \\
\text { L } \\
\text { L }\end{array}$ & $\begin{array}{l}2 \\
2 \\
1 \\
1 \\
2 \\
2 \\
2 \\
2 \\
1 \\
1 \\
2 \\
2\end{array}$ & $\begin{array}{l}\mathrm{A} \geq \mathrm{B} \\
\mathrm{A}<\mathrm{B} \\
\mathrm{A}<\mathrm{B} \\
\mathrm{A} \geq \mathrm{B} \\
\mathrm{A}<\mathrm{B} \\
\mathrm{A}>\mathrm{B} \\
\mathrm{A} \geq \mathrm{B} \\
\mathrm{A}<\mathrm{B} \\
\mathrm{A} \geq \mathrm{B} \\
\mathrm{A}<\mathrm{B} \\
\mathrm{A}<\mathrm{B} \\
\mathrm{A}>\mathrm{B}\end{array}$ & $\begin{array}{l}\mathrm{A}<\mathrm{B} \\
\mathrm{A} \geq \mathrm{B} \\
\mathrm{A}<\mathrm{B} \\
\mathrm{A} \geq \mathrm{B} \\
\mathrm{A}<\mathrm{B} \\
\mathrm{A} \geq \mathrm{B} \\
\mathrm{A} \geq \mathrm{B} \\
\mathrm{A} \geq \mathrm{B} \\
\mathrm{A} \geq \mathrm{B} \\
\mathrm{A}<\mathrm{B} \\
\mathrm{A} \geq \mathrm{B} \\
\mathrm{A}<\mathrm{B}\end{array}$ & $\begin{array}{l}3 \\
3 \\
3 \\
3 \\
3 \\
3 \\
3 \\
3 \\
3 \\
3 \\
3 \\
3\end{array}$ & $\begin{array}{c}1,2 \\
1,2 \\
1,2 \\
1,2 \\
2 \\
2 \\
2 \\
2 \\
1,2 \\
1,2 \\
1,2 \\
1,2\end{array}$ & $\begin{array}{r}.97 \\
1.00 \\
1.00 \\
1.00 \\
.94 \\
.72 \\
.94 \\
.86 \\
1.00 \\
1.00 \\
1.00 \\
1.00\end{array}$ \\
\hline
\end{tabular}

$L=$ Move to left

$R=$ Move to right

In the additional 25 sequences (Table 2) the margin at which the accretion/deletion took place was displaced right or left during the sequence. Because of the unwieldy number of sequences that result if all possible sequences are generated, a slightly constrained design was chosen that would provide all the important comparisons. In the cases in which the margin moved to the right, then the following combinations of $\mathrm{A}$ and $\mathrm{B}$ motion were used: $\mathrm{A}=$ left, $\mathrm{B}=$ right $\mathrm{A}=$ right, $\mathrm{B}=$ right $\mathrm{A}=$ right, $B=$ left. If the margin moved to the left then either $A=$ right, $B=$ left, or $A=$ left,$B=$ right.

In all cases the rate of motion could be the same in both regions (Rate 1) or could differ in either direction (Rate 1 vs Rate 2). Likewise the margin could move in the specified direction at either rate from its starting place, which was the center or $1 / 3$ left or right of the center. Thus, these sequences represent displays in which the two surfaces move in the same or opposite directions, and where the margin changed its location at a rate consistent with one or both of the regions' rate of motion.

Since randomly textured surfaces were used, it is possible to calculate on the basis of the display configuration the average rate of optical accretion/deletion specified in arbitrary units/sec and therefore the disparity of accretion/deletion across the margin. That is, it is assumed that a constant amount of accretion/deletion per unit of time is produced by a constant amount of angular displacement of the surface per unit of time (taking into account the motion of the margin). Since the textures in the two regions are similar, this relationship will hold regardless of the choice of texture elements. The resultant disparity for each sequence is presented in Tables 1 and 2 . In addition, the relevance of each sequence to the two hypotheses is indicated.

\section{Procedure}

The sequences were projected at $24 \mathrm{fps}$ and thus took approximately $5.8 \mathrm{sec}$, including a $.83-\mathrm{sec}$ stationary period at the beginning and end of each sequence. The displays were rear projected on a $36 \times 24$ in. opal glass screen and when viewed from the center of a small group of Ss were approximately $28 \mathrm{deg}$ wide and $8 \mathrm{deg}$ high. Rate 1 under these conditions was $2.5 \mathrm{deg} / \mathrm{sec}$ and Rate 2 was $5 \mathrm{deg} / \mathrm{sec}$. The edges of the field were made to be slightly out of focus in the hope of diminishing the effects of discrepant relative depth information at those locations. Ss viewed the displays binocularly.

Under the display conditions used, the contrast ratio between the black texture elements and the white screen was approximately 1:4. The displays were projected in a dimly illuminated room just light enough for Ss to record their judgments on the answer sheet provided.

The 41 sequences were duplicated and a single film containing the resultant 82 sequences was shown in each of four different random orders: one order/group of Ss. Each random order began with five sequences on which the Ss did not make judgments in order to familiarize them with the types of displays they would see.

\section{Subjects}

The Ss were 32 undergraduates fulfilling a course requirement. They served in four small groups of six to nine Ss/group. A 2-min rest period followed Trials 21,41 , and 61 .

The Ss were instructed that they would see movie sequences in which in some cases a surface on the right would be in front of a surface on the left, in other cases a surface on the left would be in front of a surface on the right, and in still other cases, neither surface would appear to be in front of the other. They were instructed to mark the scoring sheets " $R$," " $L$," or " $N$ " to correspond to these cases, respectively. In addition, they were told to pursue the place of separation between the two surfaces if it moved. It is important to note that the $S$ s were instructed to make judgments of relative depth as opposed to their reporting that one surface "covered" or "uncovered" the other. Ss have no trouble making either judgment, but since the above hypotheses were stated with respect to the perception of relative depth at an edge, the former type of judgments were used.

On each trial, Ss also made confidence judgments on a four-scale interval from "very sure" to "very unsure." The 
purpose of these judgments was to eliminate any judgmental bias that might be applied to sequences in which Ss could make the appropriate depth judgments but that were ecologically impossible.

\section{RESULTS}

Comments by the Ss: The Ss were encouraged to write comments on their data sheets both during and after the end of the experiment. No $S$ reported what could be interpreted as difficulty in making the judgments required. By and large, the Ss adopted a "naive" attitude as evidenced by the fact that only one $S$ indicated, "Since it's just a movie, there really can't be any depth there."

On sequences in which there was accretion/deletion on both sides of a margin approximately $80 \%$ of the Ss reported one of two descriptions. The first type referred to displays in which the margin was stationary-these were described as looking as if there were two textured surfaces going around rollers that abutted at a crack (the margin), with one roller being closer to them than the other. In cases in which the margin moved in addition to having accretion/deletion on both sides of the margin, Ss often reported similar descriptions and in addition reported the surface seen in front as shrinking or growing. Thus, in both cases they reported edge-depth but not occlusion.

\section{Judgments of Relative Depth}

The proportion of judgments left in front or right in front across Ss, for each sequence, is presented in Fig. 3. The proportion of judgments "neither in front" can be obtained by subtracting the sum of the two given proportions from 1.00. The shaded areas represent judgments in the predicted direction. With respect to $\mathrm{H} 1$ the proportion of judgments correctly predicted $=.98$ (Tables 1 and 2$)$; thus $98 \%$ of the judgments were in the predicted direction (range $=.91-1.00$ ), while with respect to $\mathrm{H} 2$ the proportion was $=.87$ (range $=.53-1.00$ ). Considering the intersection of these two sets of sequences, there are 20 sequences that are relevant to $\mathrm{H} 2$ only and the corresponding value for these was $=.75$. The difference between $\mathrm{H} 1$ and $\mathrm{H} 2$ is highly significant $\left(\chi^{2}\right.$ median test $=1380, \mathrm{df}=1, \mathrm{p}<.001$, two-tailed test); however, all three values are also significantly different from the chance value of $1 / 3(\mathrm{H} 1: \mathrm{t}=7.3, \mathrm{df}=20$, $\mathrm{p}<.001 ; \mathrm{H} 2: \mathrm{t}=3.55, \mathrm{df}=40, \mathrm{p}<.001 ;$ and $\mathrm{H} 2 \cap \mathrm{H} 1: \mathrm{t}=3.04$, $\mathrm{df}=19, \mathrm{p}<.005$, all two-tailed tests)

Since the sequences were constructed in such a way that the right-left reversal of each sequence was shown, it is possible to see if there are any assymetries in the data as a result of whether there was accretion or deletion vs preservation ( $\mathrm{H} 1$ sequences), or whether there was relatively more accretion or relatively more deletion (H2 sequences). Such a possibility is not supported by the data as there is not any significant difference between such pairs of sequences $(t<1.0, \mathbf{d f}=18$, n.s. $)$

Similarly, it is necessary to examine the data for any systematic effects due to the relative velocities of the two surfaces. It is conceivable that motion parallax information might act in some additive way with optical accretion/deletion, and thus in sequences where the two are consistent there would be greater accuracy of prediction. Although there is a slight indication that this might be the case (consistent sequences $=.93$ vs inconsistent sequences $=.81$ ) the difference does not reach statistical significance $\left(\chi^{2}\right.$ median test $\left.=1.62, \mathrm{df}=1, \mathrm{p}>.05\right)$.

An important finding is the strong relationship between the amount of disparity and the strength of prediction. This relationship can be observed in Fig. 3 where the sequences are grouped according to amount of disparity. The Speamman rank correlation coefficient $\left(r_{s}\right)$ between the amount of disparity (for sequences in which the disparity is greater than 0 ) and the success of prediction of Ss' judgments $=.68$ (corrected for ties), which is significantly greater than $0(t=5.40, \quad d f=34, \quad p<.001$, two-tailed test). This correlation was not anticipated and has important implications which will be discussed later.

\section{Confidence Ratings}

In general the confidence ratings correlate highly with the accuracy of prediction of the judgments of relatjve depth $\left[\mathrm{r}_{\mathrm{s}}=.89\right.$ (corrected for ties), $\mathrm{t}=12.1, \mathrm{df}=39, \mathrm{p}<.001$, two-tailed test]. The average rating was 3.2 ; those that were consistent with the hypotheses were rated on the average 3.3, while those that were inconsistent were rated on the average 2.3

\section{DISCUSSION}

The results of the present study support the analysis of the optical consequences of edge occlusion and the prediction of the perception of an edge-with-depth. The fact that $98 \%$ and $87 \%$ of $\mathrm{Ss}$ judgments of depth were correctiy predicted by $\mathrm{H} 1$ and $\mathrm{H} 2$, respectively, attests to the strength of such information in specifying relative depth in the absence of any traditional pictorial or kinetic cues for depth.

Although the initial hypothesis, $\mathrm{H} 1$, is a significantly better predictor of Ss' judgments than is $\mathrm{H} 2$, both are confirmed onsiderably better than chance. Of course, the two are not mutually exclusive; $\mathrm{Hl}$ is logically nested within $\mathrm{H}_{2}$. The existence of a significant correlation between the amount of disparity of the rate of accretion/deletion and the accuracy of prediction of Ss' judgments indicates that $S$ s are sensitive to such a parameter and that a sufficient framework for dealing with kinetic stimulus information for edge depth should include it. Thus, $\mathrm{H} 2$ is to be preferred.

The results coupled with the verbal reports of Ss suggest that it

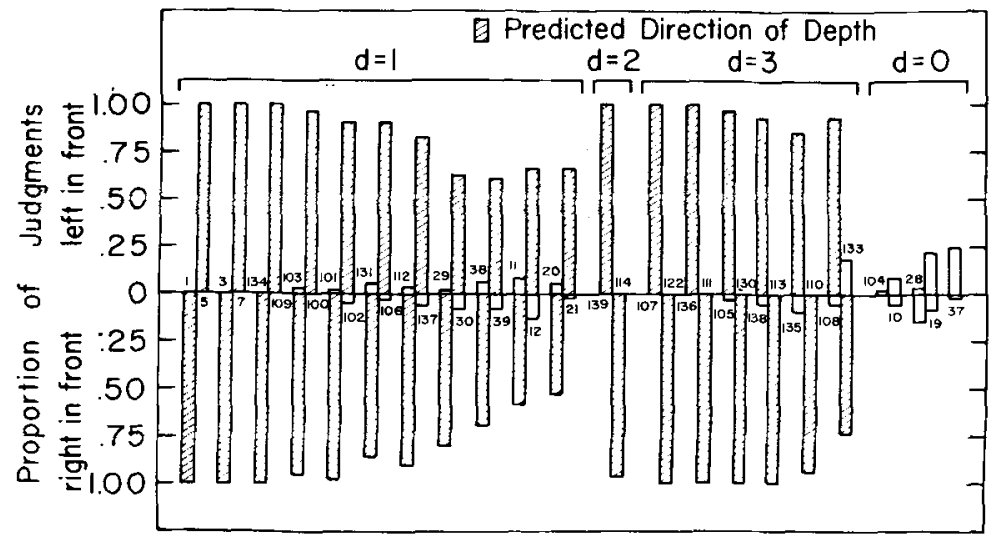

Fig. 3. Proportion of judgments of relative depth greater on the right or on the left side for each sequence. Shaded areas indicate judgments in the predicted direction. Sequences paired together represent right-left reversals. For a full description of each sequence consult Tables 1 and 2 . 
is possible to distinguish between edge-depth with and without occlusion on the basis of the optical accretion/deletion information that is present. That is, Ss shown the displays used in this experiment will quite willingly describe the majority of them as involving both a separation in depth of two surfaces as well as one surface occluding (extending in front of) another. 6 Their reports thus indicate that there is information in these displays for both the direction of depth at an edge (relative depth) as well as the screening, hiding, or covering of one surface by another. This is only true, however, for the displays that are related to $\mathrm{H} 1$. In the remainder of the displays that involve optical accretion/deletion on both sides of a margin, Ss report edge-depth but not occlusion; they do not, in these cases, report that one surface extends behind the other.

The disparity formulation $(\mathrm{H} 2)$ has led to the construction of displays in which Ss report a type of contour that seems to have been previously unreported. Specifically, when there is accretion on one side of a margin and deletion on the other side, and when the rate of accretion/deletion is the same on both sides of the margin, Ss report seeing a line or contour in the field that does not "belong" to any part of the field. This contour can be described as a very thin "pencil" that appears to be on top of the surfaces. Such contours contradict the traditional postulate that contours have either a "one-sided or two-sided function (Koffka, p. 182)." Thus, instead of belonging to one or two surfaces, i.e. being an edge, these contours belong to neither surface.

The evidence for the utility of the disparity formulation does, however, raise several difficulties. The most important of these involves the calculation of the rate of accretion/deletion. One can ask, for example, if the rate is with respect to angular units per interval of time or if $\mathrm{it}$ is with respect to structural properties of the optical texture. The first alternative would suggest for the present displays that the perception of edge depth would be simply related to the relative angular velocities of individual texture elements. If this were the case, then the perception of edge depth would have been significantly better for the sequences in which motion parallax information was consistent with accretion/deletion information. However, no significant relationship was found. The latter suggestion seems to be indicated but there exists at the present no adequate formulation of what structural features of the optical texture constitute texture elements. One possibility that needs to be tested is that there is a kind of "normalization" involved in the calculation of the rate of accretion/deletion. What this might involve would be a measure that reflects some average characteristic of the optical texture such as average angular size of "significant" components of the texture. If this were the case, then the perceptual system could respond to the rate of accretion/deletion as the number of such elements that were deleted or accreted per unit of time. This possibility could be tested by the construction of displays similar to the ones used in this investigation but that differ in that the textures in the two regions do not have equal densities. If this were the case, then translation of the textures at an equal velocity would yield unequal rates of accretion/deletion. Similar manipulations are possible in which the size of texture clusters is varied. Experimental work currently under way is designed to investigate these possibilities.

\section{Edge Occlusion and Phenomenal Permanence}

Although it has not been emphasized in the previous discussion, the problem of the perception of occlusion at an edge is clearly related to the problem of the perception of the continued existence of an object after it has disappeared from sight--phenomenal permanence in spite of sensory impermanence. That is, normally when we speak of something going behind another thing, the continued existence of the occluded object is implied, despite the fact that it may no longer be projected to the station point where the eye is. Thus, there are two aspects to the perception of an occluding edge: $(1)$ the relative depth of the two surfaces, and (2) the phenomenal permanence of the occluded surface. Michotte (1964) and his collaborators have explained the latter kind of perception as "amodal completion." It is, to them, the perception of an object in the absence of any modal (sensory) data for that object.

An example of an event that would be evidence of amodal perception for Michotte is the following: A small rectangle (B) moves across a screen and becomes progressively hidden by a larger stationary rectangle (A). Os will unanimously report (under the appropriate display conditions) that $B$ moves behind $A$, and that it continues to exist in its transit behind A (Burke, 1952; Reynolds, 1967; Sampaio, 1962).

The basic aspect of Michotte's explanation of this phenomenon is a statement of the factors or conditions that determine "belongingness" of the delimiting contour between $A$ and $B$. According to Michotte, these are the same gestalt factors that determine perceptual organization-similarity, proximity, good continuation, common fate, etc. (Koffka, 1935).

Once this contour has been assigned a one-sided function, Michotte then calls upon the principles of figure-ground organization to account for both the tridimensionality and the phenomenal permanence of the occluded rectangle. Since the contour belongs to A, $A$ takes on the role of figure and $B$ the role of ground. This has as its consequence the fact that $A$ is seen in front of $B$, and $B$ is seen as extending behind $A$.

The approach suggested here is considerably different. According to the analysis presented earlier, it is possible that Ss perceived B sliding behind A because the optical transition that is presented to them is one that is specific to changes of occlusion and depth at an edge, e.g., one that will always stem from changes in occlusion. Rather than having to make assumptions about factors of organization that determine contours and edge-depth, the present analysis provides a way of stating the information in the changing aspects of stimulation that potentially specify the relative depth at an edge as well as occlusion. In addition, the present analysis suggests that it is not necessary to consider contour formation and contour belongingness within two separate frameworks; both are entirely predictable from a consideration of the optical accretion/deletion that is present. With the type of displays used in this investigation the contour separating two surfaces is specified only by the kinetic accretion/deletion information and which surface the contour "belongs" to (the direction of depth) is also specified only by the accretion/deletion information.

We assume that the specification of change of occlusion means to the perceptual system that the occluded surface continues to exist. Presumably, there are other kinds of kinetic transformations that specify impermanence. The basic assumption is that there have been biological pressures over the evolutionary history of terrestrial organisms to be able to discriminate between these two supposed types of optical transitions. [Examples of both types are presented in a paper and $16-\mathrm{mm}$ film entitled, "The change from visible to invisible: A study of optical transitions" (Gibson et al, 1968; Gibson, 1968b).]

\section{Qualitative Observations}

A number of informal experiments have been carried out aimed at exploring and clarifying the nature and role of optical accretion/deletion as well as the nature of the mechanisms that are responsible for the detection of such information. Two of these experiments that were for the most part informal presentations of film sequences to sophisticated observers are briefly described below.

(1) Since the formal experimentation always involved an edge that was a straight line, it seemed desirable to examine cases in 
which an irregularly shaped edge was used. Several sequences were constructed in which there were several irregularly shaped regions after the fashion of ink blobs. In all cases $S$ s reported seeing the predicted direction of depth. Thus, at a first approximation, the shape of the margin at which accretion/deletion occurs does not appear to be critical. An example of these displays is shown in Gibson (1968b).

(2) In the interest of further experimentation and to make sure that there was nothing critical about the animation procedures or the textures that were used, several displays were constructed and photographed by a computer-operated CRT display system. ${ }^{7}$ One display format was identical to that used in Fig. 3. The display surface was randomly filled with dots so that there was a $50 \%$ chance of a dot appearing in any particular location, and either or both regions were displaced. The same procedure was followed with displays composed of larger clusters of dots (5-6 dots/cluster) and still larger clusters (10-15 dots/cluster). In general, Ss reported the predicted direction of depth al though the effect is somewhat attenuated with the small-dot textures. Further research aimed at an understanding of the role of cluster size is currently under way.

Another display format was used in which the field consisted of a square divided up into an outer frame, an inner frame, and a square within the inner frame. The texture was $50 \%$ filled with random dots. The texture in the region of the inner frame was made to translate from right to left with its elements being deleted and accreted at the appropriate point. Ss across a wide range of rates of projection report seeing a stationary frame with a window in it and a surface moving behind the frame, as well as a small square inside that floats in front of the moving surface. Virtually all Ss who were queried reported that the outer frame and the inner square were at the same depth, i.e., in the same plane. An example of such a sequence is in Gibson (1968b).

\section{CONCLUSION}

On the basis of the results and discussion presented above, it seems reasonable to conclude that a source of information for the visual system about the layout and location of surfaces in the environment has been uncovered. By means of an analysis of the optical consequences of occluding surfaces and the results of change in occlusion, it has been possible to isolate a specific type of transformation or transition in the optic array that provides an $O$ with information about the existence of an edge, the direction of depth at the edge, and whether the edge is occluding or not.

The crucial factor appears to be the differential rate of optical accretion and deletion on both sides of a margin in the optic array. The rate of accretion/deletion can be independent of both the rate and direction of motion of the surfaces that project into the array. By appropriate manipulations of both the disparity of accretion/deletion and the locus of this transformation it is possible to induce the perception of directional depth at an edge in the absence of any traditional static or kinetic cues for depth. Similarly, it is possible to induce the perception of depthless contours that also exist only as a consequence of specific temporally defined transformations of optical structure. Taken together with other observations and experiments (Gibson, 1966, 1968a), ${ }^{3}$ the present study provides strong support for the importance of motion-carried factors in the perception of surface layout, including the relative location, rigidity, and perhaps even phenomenal permanence of parts of the environment, as well as providing additional data for a theory of ecological optics (Gibson, 1966).8

\section{REFERENCES}

BRAUNSTEIN, M. L. Sensitivity of the observer to transformations of visual field. Journal of Experimental Psychology, 1966, 72, 683-689.

BURKE, L. On the tunnel effect. Quarterly Journal of Experimental Psychology, 1952, 4, 121-138.

CHAPANIS, A., \& McCLEARY, R. A. Interposition as a cue for the perception of relative distance. Journal of General Psychology, 1953 $48,113-132$.

DINNERSTEIN, D., \& WERTHEIMER, M. Some determinants of phenomenal groupings. American Journal of Psychology, 1957, 70, 21-37.

GIBSON, J. J. The senses considered as perceptual systems Boston: Houghton Mifflin, 1966.

GIBSON, J. J. What gives rise to the perception of motion? Psychological Review, 1968a, 75, 335-346.

GIBSON, J. J. The change from visible to invisible: A study of optical transitions. 16-mm Film. Psychological Cinema Register, $1968 \mathrm{~b}$.

GIBSON, J. J., KAPLAN, G. A., REYNOLDS, H., \& WHEELER, K. The change from visible to invisible: A study of optical transitions. Perception \& Psychophysics, 1969, 5, 113-116.

HAY, J. Optical motions and space perception: An extension of Gibson's analysis. Psy chological Review, 1966, 73, 550-565.

HELMHOLTZ, H. von. Handbook of physiological optics. Vol. 3 (J. P. C. Southall, Ed.). Dover Publications, 1962.

JOHANNSON, G. Perception of motion and changing form. Scandinavian Journal of Psychology, 1964, 5, 181-208.

KOFFKA, K. Principles of Gestalt psychology. New York: Harcourt, Brace, \& World, 1935.

METZGER, W. Gesetze des Sehens. Frankfurt: Waldemer Kramer, 1953

MICHOTTE, A., THINGES, G., \& CRABBE, G. Les complements amodaux des structures. Louvain: Publications Universitaires de Louvain, 1964. (Amodal perception and perceptual organizations, trans. by T. G. R. Bower and D. J. Bower, Cornell University, 1964.)

RATOOSH, P. On interposition as a cue for the perception of distance. Proceedings of the National Acedemy of Science, 1949, 35, 257-259.

REYNOLDS, H. N. Temporal estimation in the perception of occluded motion. Unpublished doctoral dissertation, Cornell University, 1967

SAMPAIO, A. C. La translation des objects comme facteur de leur permanence phenomenale. In A. Michotte et al, Causalité, permanence et realité phenomenales. Louvain: Studia Psychologica, 1962. Pp. 277-298.

\section{NOTES}

1. Based on a PhD dissertation submitted to Cornell University. The support and guidance of Dr. James J. Gibson is gratefully acknowledged. The research was carried out while the author was a Public Health Service Predoctoral Fellow. It was partially supported by the above source and by research grants to Dr. James J. Gibson from the Office of Naval Research (NONR 14-67-A-0077-0005) and the National Science Foundation (GS-1993). Portions of these data were presented at the Eastern Psychological Association meetings, A pril 1968.

2. Address: Department of Psychology, Stanford University, Stanford California 94305

3. Also: Gibson, J. J. An outline of experiments on the direct perception of surface layout. Draft, February 1968.

4. Following the terminology of Gibson (1966, and Note 3 above), we use station point to refer to a potential point of observation in an environment. An optic array at a station point corresponds to the specific pattern of energy surrounding that point.

5 . The texture was constructed by photographic means and consists of approximately $50 \%$ black and white. Figure 2 is an example of the texture used.

6. Although verbal descriptions were not actually requested in this experiment, the author has shown the same displays to large numbers of Os and asked for verbal descriptions. In virtually every instance these descriptions confirm the statements made in this section.

7. The author would like to express his appreciation to Dr. Bela Julesz Bell Telephone Laboratories, for his support and assistance in generating these sequences.

8. The author has prepared a short demonstration film illustrating some of the displays used in the above experiment. Questions concerning the availability of copies of this film should be directed to him.

(Accepted for publication February 23, 1969.) 